\title{
A QUEBRA DE PARADIGMAS DO SUPREMO TRIBUNAL FEDERAL EM DIREITO À SAÚDE E A AUSÊNCIA DA CONSISTÊNCIA TEÓRICA
}

\section{THE BREACH OF PARADIGMS OF THE SUPREME FEDERAL COURT IN THE RIGHT TO HEALTH AND THE ABSENCE OF THEORETICAL CONSISTENCY}

FERNANDO RISTER DE SOUSA LIMA

Professor Doutor na Faculdade de Direito da Universidade Presbiteriana Mackenzie (FDIR-UPM). Professor Permanente do Mestrado em Direito da Informação da FMU. Agradece-se à Coordenação de Aperfeiçoamento de Pessoal de Nível Superior (Capes) pelo apoio no financiamento do projeto de pesquisa, cujo desenvolvimento resultou também neste artigo. E-mail: fernando.lima@mackenzie.br.

\section{RESUMO}

Objetivo: O estudo objetiva analisar as decisões do Supremo Tribunal Federal, com o propósito de identificar julgamentos proferidos no período de 2010 a 2013, e verificar se houve incorporação de novos conceitos sobre o direito à saúde na sua jurisprudência.

Metodologia: A metodologia empregada é a pesquisa bibliográfica, por meio da análise de decisões jurisprudenciais do Supremo Tribunal Federal, delimitada ao período de 2010 a 2013.

Resultados: A leitura dos acórdãos denota como direta ou indiretamente estão fundamentados na ausência dos parâmetros. É possível também falar-se em novos parâmetros e não em ausência de critérios. Prefere-se a ausência de critérios ante 0 entendimento de que os rígidos pontos de partida anteriores moldaram por décadas a atuação judicial e a sua retirada acabou fragilizando a argumentação jurídica, a 
ponto de não se discutirem questões pertinentes. Os acórdãos dispõem em oferecer esperança como fonte de cura. Uma linguagem muito longínqua da ciência médica e sem qualquer critério de gestão do dinheiro público instaurou-se nos novos julgamentos da Corte. A ausência de consistência jurídica fica também evidenciada com a completa despreocupação em enfrentar a argumentação jurídica oferecida pela política. Tudo está tão conforme os novos conceitos que não se justifica argumentar ou enfrentar as teses jurídicas da Administração Pública. Eis o novo paradigma jurisdicional em direito à saúde.

Contribuições: A contribuição central do presente trabalho está na análise de decisões da Suprema Corte a fim de identificar o tratamento dado a questões de direito à saúde..

Palavras-chave: Ministros proativos; nova racionalidade; jurisprudência do Supremo Tribunal Federal; papel do Direito.

\section{ABSTRACT}

Objective: The study aims to analyze the decisions of the Supreme Federal Court, with the purpose of identifying judgments handed down from 2010 to 2013, and to verify whether new concepts about the right to health have been incorporated into its jurisprudence.

Methodology: The methodology used is bibliographic research, through the analysis of jurisprudential decisions of the Federal Supreme Court, limited to the period from 2010 to 2013.

Results: The reading of the judgments shows how directly or indirectly they are based on the absence of parameters. It is also possible to talk about new parameters and not in the absence of criteria. The absence of criteria is preferred due to the understanding that previous rigid starting points have shaped judicial action for decades and its withdrawal has weakened the legal argument, to the point of not discussing relevant issues. Judgments offer hope as a source of healing. A very distant language of medical science and without any criterion for the management of public money was established in the Court's new judgments. The lack of legal consistency is also evidenced by the complete lack of concern in facing the legal arguments offered by the politics. Everything is so in line with the new concepts that there is no reason to argue or face the legal theses of the Public Administration. This is the new jurisdictional paradigm in the right to health.

Contributions: The central contribution of the present paper is the analysis of the Supreme Court decisions in order to identify the treatment given to issues of right to 
health.

Keywords: Proactive ministers; new rationality; jurisprudence of the Supreme Federal Court; role of law.

\section{INTRODUÇÃO}

O texto ora introduzido é resultado de uma pesquisa realizada no período de 2010 a 2013, financiada pela Coordenação de Aperfeiçoamento de Pessoal de Nível Superior (Capes) - por meio de seu programa de doutorado sanduíche, que se realizou nas Faculdades de Direito da Pontifícia Universidade Católica de São Paulo (PUC/SP) e na Universidade de Estudos de Macerata (UNIMC), Itália. Trata-se, pois, de um recorte da tese de doutorado defendida em 2013 na área de concentração em Filosofia do Direito e do Estado, na primeira instituição citada, precisamente apresentada como pesquisa em Sociologia Jurídica.

Os acórdãos analisados foram coletados do sítio eletrônico do Supremo Tribunal Federal, especificamente no link de jurisprudência. Para a busca, foram escolhidas as expressões: "direito à saúde" e "separação dos poderes", primordialmente de forma isolada e, em seguida, em conjunto. Esse procedimento de pesquisa foi utilizado inúmeras vezes em momentos temporais completamente diversos. Na escolha das decisões a serem pormenorizadamente tratadas na tese, preliminarmente, optou-se por dois critérios: (i) temporal, de ordem objetiva; (ii) enfrentamento do direito à saúde pela óptica explícita, ou implícita, da separação dos poderes, de natureza subjetiva, uma vez que a escolha da decisão reclamou da lente do observador, especialmente na visão implícita.

Na primeira escolha, como regra inicial, optou-se por acórdãos publicados entre o início de 2009 e o fim de 2012, com o condão de outorgar ares de atualidade à pesquisa. Depois disso, sem menoscabo do marco temporal, ganharam espaço no material coletado, acórdãos anteriormente julgados e identificados como relevantes à compreensão do raciocínio travado naqueles estudados. Gradativamente, a quantidade de julgados anteriores à baliza temporal 
traçada agigantou-se, a ponto de o padrão inicial não mais se tipificar. Por outro lado, restou, no viés metodológico, ainda incólume o outro padrão inicial de pesquisa como critério investigativo: "direito à saúde" e "separação dos poderes".

Do material coletado, não se excluiu determinado grupo de técnicas processuais, como por exemplo, agravo regimental e pedido de suspensão de segurança ante o entendimento de que a sua mantença traria riqueza à pesquisa, a resultar num material heterogêneo, da perspectiva procedimental dos julgamentos. Bem por isso, foram analisados acórdãos de julgamento de recursos extraordinários, de agravos regimentais por indeferimento de recurso extraordinário, de pedidos de suspensão de tutela antecipada, de ação cautelar e de recurso ordinário em mandado de segurança.

Depois da escolha desses critérios de seleção, a coleta final resultou em setenta e um acórdãos, os quais foram lidos, relidos e, por fim, estudados minuciosamente, um a um. O resultado é o avante escrito. Desse universo, escolheram-se vinte decisões que tiveram papel significativo no resultado da pesquisa. Os pontos principais destes julgados foram transcritos em notas de rodapé.

A pesquisa originária teve um enfoque diferente do apresentado neste artigo. Ambas são perspectivas muito diversas de análise, porém, o que interessa neste introito é informar como se organizou o material a seguir.

$O$ texto à frente apresenta o resultado de uma coleta de fontes documentais, por meio da pesquisa realizada no sítio do Supremo Tribunal Federal no período mencionado linhas atrás, sob a justificativa de investigar a existência ou não de uma racionalidade do Supremo em direito à saúde, signo de uma postura ativa dos ministros desta Corte, diversa dos contornos tradicionais, ligada propriamente a um magistrado inerte. O texto representa um estudo dos acórdãos proferidos nos anos de 2010 a 2013, não abrangendo precedentes posteriores ao citado período, contudo as atuações pretéritas foram analisadas quando diziam respeito ao objeto de estudo.

O papel exercido por três ministros, nomeadamente Celso de Mello, Marco Aurélio Mello e Gilmar Ferreira Mendes, reportando-se ao material coletado, chama 
atenção. Suas atuações intelectuais e de liderança na Suprema Corte romperam paradigmas da dogmática jurídica e, consequentemente, cunharam novos valores de postura judicial diante dos demais poderes (tripartição dos poderes), de interpretação das normas constitucionais programáticas, de direito público subjetivo indisponível e de concretude da norma constitucional.

\section{MUDANÇAS DE PARADIGMAS EM JULGAMENTOS DO SUPREMO TRIBUNAL FEDERAL EM SEDE DE DIREITO À SAÚDE}

Nas decisões examinadas, os paradigmas foram notados pela mudança de sentido dos conceitos dogmáticos anteriormente utilizados nos julgamentos do Supremo Tribunal Federal. Com isso, a pesquisa observou a evolução das decisões, tendendo a uma mudança de racionalidade a partir de atuações dos referidos ministros, porque as suas decisões introduziram valores e conceitos que foram incorporados a decisões posteriores dos próprios ministros paradigmas e sobretudo dos demais magistrados. Notou-se também a instauração de nova forma de julgar da Corte Suprema em casos semelhantes, aproximando-se da ratio demonstrada nas decisões dos citados ministros.

Essa incorporação de novos conceitos, contudo, não se concretizou sem prejuízo da falta de consistência teórica, a qual, em vários julgados, mostrou-se muito mais próxima da política do que propriamente do direito. $\mathrm{O}$ artigo utilizará como exemplo o conceito dogmático da reserva do possível para demonstrar tal carência de consistência teórica motivada pela dificuldade em aplicar novos parâmetros conceituais gerados pela reiterada atuação dos três citados ministros do STF.

\section{I - Ministro Celso de Mello}

O Ministro Celso de Mello foi nomeado em 30.06.1989 como ministro da Excelsa Corte e empossado em 17.08.1989, oriundo da carreira do Ministério 
Público do Estado de São Paulo. Foi ministro decano da referida Corte. A sua atuação jurisdicional teve um papel fundamental na própria formação do conceito de direito à saúde como direito público subjetivo indisponível e também no ideário de que as normas programáticas não podem tornar-se promessa inconsequente. Dogmaticamente, na sua atuação merece destaque a incorporação da ideia da saúde como direito subjetivo independente da existência ou não do recurso para atendê-lo. De outro modo, ressalta-se a mudança de um conceito clássico da dogmática constitucional segundo qual normas programáticas são guias para os gestores públicos, que devem implementá-las quando for possível, ao seu critério. Tais normas jurídicas seriam normas não vinculantes. Os manuais de direito constitucional reiteradamente repetiram essa ideia por anos a fios. Isso mudou muito graças ao ministro em questão.

Para compreender a magnitude da atuação do Ministro Celso de Mello, não é demais remontar à guinada constitucional que pretendiam os constituintes de 1988, quando brindaram o país com uma nova Carta Magna, repleta de direitos, conceitos novos e uma vasta e conflitante base ideológica. Simbolicamente, forjouse uma carta de direitos para uma nação com uma ainda frágil democracia, pouco desenvolvimento e socialmente heterogênea.

Exatamente nesse cenário, tomou posse José Celso de Mello Filho. Discreto na sua vida pessoal e nas suas falas, gradativamente, o ministro foi impondo ideologicamente uma nova racionalidade na forma de julgar o direito à saúde e as normas programáticas. A bem da verdade, teve a lucidez de pensar fora do seu tempo, ir além, propriamente forjando - numa construção histórica - o conceito de direito à saúde indisponível, mesmo diante da incapacidade estatal.

O Ministro Celso de Mello, em sua atuação, deparou-se com paradigmas extremamente difíceis de serem rompidos, dos quais, é nítida e necessária a constatação de que o Supremo Tribunal Federal é, sim, uma Corte de forte dimensão política, consoante se aduz do julgamento da Arguição de Descumprimento de Preceito Fundamental 45/DF. Consequentemente, há a constatação de que o Poder Judiciário tem legitimidade para a implementação de políticas públicas, quando configurada a abusividade da atuação ou mesmo da não 
atuação estatal. Talha-se, nesse prisma, uma nova perspectiva ao conservador princípio da separação dos poderes, como o próprio ministro grafa, no citado julgado:

[...] parece-nos cada vez mais necessária a revisão do vetusto dogma da Separação dos Poderes em relação ao controle dos gastos públicos e da prestação dos serviços básicos no Estado Social, visto que os Poderes Legislativo e Executivo no Brasil se mostraram incapazes de garantir um cumprimento racional dos respectivos preceitos constitucionais.

A influência do Ministro Celso de Mello nos julgamentos em direito à saúde, reiteradamente, materializa-se nas decisões da Suprema Corte como paradigma propriamente dito; quer dizer: um ponto de partida seguro, confiável e respeitado. São inúmeros os precedentes nessa linha, valendo citar, exemplificadamente, as seguintes decisões: Agravo de Instrumento 507.072/MG - Relator Ministro Joaquim Barbosa, Agravo de Instrumento 597.182AgR/RS - Relator Ministro Cezar Peluso e Agravo de Instrumento 607.646/SC - Relator Ministro Ricardo Lewandowski. Nas três decisões, serve como paradigma o Agravo Regimental em Recurso Extraordinário 271.286/RS, da relatoria do Ministro Celso de Mello. Dentro do material coletado, essa decisão, no que diz respeito ao fornecimento de remédio, é lugar-comum, citado muitas vezes. Nos acórdãos em comento, nos dois primeiros, legitimou-se o bloqueio de valores dos cofres públicos a fim de assegurar 0 fornecimento gratuito de remédios. No último, o ministro fundamentou decisão que garantia medicamento especial para tratamento de doença conhecida como Esclerose Lateral Amiotrófica (ELA).

O reiterado acórdão AgR 271.286-RS, relado pelo Ministro Celso de Mello, foi proferido em 19.09.2000, num cenário racional muito adverso se comparado ao atual ambiente da Suprema Corte. Naquele momento, ainda era forte uma racionalidade voltada para a pouca intervenção do Poder Judiciário em direitos sociais; mas é verdade, por outro lado, que o direito à vida já contava com um tratamento diferenciado. Enquanto isso, as demais perspectivas do direito à saúde ainda eram vistas com reserva, ancoradas na aplicação do princípio da separação dos poderes, em nítido viés liberal. O famoso decisum alude ao fornecimento de 
medicamentos para combater a HIV/AIDS. Em síntese, o Ministro Celso de Mello inseriu no debate processual daquele processo conceitos como direito público subjetivo à saúde, acenando que a interpretação da norma constitucional programática não pode transformá-la em promessa inconsequente, com o arauto de garantir que o direito à saúde seja resguardado.

\section{II - Ministro Marco Aurélio Mello}

Marco Aurélio de Farias Mello foi empossado como ministro da Corte Suprema em 13.06.1990. Teve rápida passagem na advocacia e no Ministério Público do Trabalho. Atuou como juiz do trabalho de 1978 a 1981, quando tomou posse como ministro no Tribunal Superior do Trabalho. Possivelmente em razão de sua atuação profissional anterior ao Supremo Tribunal Federal ter sido essencialmente ligada ao direito do trabalho, ideologicamente sempre teve uma postura jurisdicional mais voltada ao Estado Social do que ao Liberal. O assistencialismo sempre esteve presente em seus votos e, por vezes, não procurou buscar consistência teórica em seus julgamentos, talvez por acreditar na simplicidade de escolha entre os valores em litígio. Pautou-se, o ministro, muito mais pela busca de um fim que acreditava ser o mais justo.

As atuações do ministro em direito à saúde tipificam-se como um sentimento puro, de fundo ideológico. Sua postura é sempre em favor da concretude do direito em comento, como se só existisse uma opção a ser escolhida, até por este motivo, despreocupada em demonstrar uma refinada justificativa constitucional. Na verdade, o ministro julgou com um posicionamento rígido, irrenunciável, o qual contribuiu para a formação da racionalidade atual da Suprema Corte. Seu papel foi importante porque marcou uma postura ideológica forte em favor da quebra do paradigma da separação dos poderes como máxima liberal.

Em sintonia com o exposto e à luz da releitura dos votos do Ministro Marco Aurélio de Mello, os seus argumentos demonstram uma verbalização emocional, chegando, em algumas situações, a um desabafo. Nota-se que nos argumentos deste ministro, o homem da lei fica de lado para defender o jurisdicionado que se 
sente injustiçado com as promessas constitucionais não cumpridas, a ponto de se extrair dos seus votos máximas como: “a viúva não ficará mais pobre”. No aspecto, vale transcrever:

O SENHOR MINISTRO MARCO AURÉLIO (PRESIDENTE) - Estou desprovendo e mantendo o acórdão. O recurso é da União. Certamente, com esse tratamento. A viúva não ficará mais pobre!. [...] Essa denominada reserva do possível, no tocante ao Estado, leva-me à indignação como contribuinte, como cidadão, como juiz, pois, se for realmente empolgada e aceita, teremos desculpa para tudo, porquanto, desde que me conheço, o Estado, em que pese a grande carga tributária, luta contra escassez de receita, mas luta porque tem despesas excessivas, principalmente com a máquina administrativa e a dívida interna (BRASIL, STF, Recurso Extraordinário 368.564/DF, j. 13.04.2011).

\section{III - Ministro Gilmar Ferreira Mendes}

Antes do ingresso do Ministro Gilmar Ferreira Mendes no Supremo Tribual Federal já havia em curso nesta Corte o debate em torno do direito à saúde e da sua concretude por meio de decisões judiciais, bem como uma racionalidade direcionada no sentido da sua efetivação, quando omissos os demais poderes da República e configuradas situações excepcionais. No entanto, não obstante o palco do debate ser a Corte Constitucional, boa parte das discussões e das justificativas para a concessão gravitava muito mais em torno do debate infraconstitucional do que propriamente das discussões constitucionais, como se pode evidenciar nos Agravos de Instrumento 232.469-RS e 238.328-RS, ambos relatados pelo Ministro Marco Aurélio.

Nesses arestos, garantiu-se o fornecimento de medicamentos por parte do Município de Porto Alegre, em que pese a argumentação do ente público agravante, no sentido da não regulamentação legal da obrigatoriedade do fornecimento dos remédios. Contudo, buscou-se fundamento na existência de outros convênios entre os poderes públicos e em legislações estaduais, mesmo que implicitamente, e, ao final do decisum, fez-se menção à Constituição Federal. Desse modo, da sua leitura não se extrai uma elevada consistência "teórico-constitucional" a respeito do litígio a ser dirimido. 
Em similar contexto, enfileira-se o Agravo Regimental no Recurso Extraordinário 273.042-4/RS, da relatoria do Ministro Carlos Velloso. Aqui, o Município de Porto Alegre também leva seu pleito à Corte Suprema com o propósito de imediatamente cessar a sua obrigação de fornecer medicamento ao recorrido sob a justificativa de que a obrigação é do Estado do Rio Grande do Sul. O recurso, igualmente, foi indeferido, porém, ainda sem uma justificativa em nível constitucional. Pelo seu teor, garantiu-se o direito à saúde, mas sem bem saber o porquê; quase que numa perspectiva puramente ideológica. Com esse mesmo diapasão, tem-se o Agravo Regimental no Recurso Extraordinário 255.627-RS (o Ministro Nelson Jobim foi o relator), cuja fundamentação, além de não ter consistência teórico-constitucional, inclinando-se por uma postura meramente ideológica, mais próxima da comunicação política do que da jurídica, serve-se meramente de precedentes similares, numa destacada simplificação da questão. Por outro lado, extraindo-se a questão ideológico-político, a racionalidade se aproxima do common law, numa versão mais empobrecida.

Outro aspecto notado nesse cenário "Pré-Ministro Gilmar" alude ao fato de que a intervenção do Judiciário é bem definida em questões extremas, como o tratamento de AIDS, conforme pode-se ver no acórdão do Recurso Extraordinário 236.644/RS, que teve como relator o Ministro Maurício Corrêa. A propósito, a Corte Suprema atuava em casos de risco de morte, situações extremas que reclamavam o básico, como por exemplo, remédio para a AIDS. Nesse extremo cenário, já havia uma racionalidade no apreço da concretude do direito à saúde, notadamente pelas intervenções do Ministro Celso de Mello.

Em razão de todo o exposto, com o fito de analisar um julgado que abarque as duas perspectivas, isto é, a da abordagem infraconstitucional (neste caso aliada a pouca consistência teórico-constitucional) e a da busca da concretude do direito à saúde em razão da visualização de casos de risco de morte, confere-se o Agravo Regimental no Recurso Extraordinário 259.508-RS (Relator Maurício Corrêa), publicado em 16 de fevereiro de 2001. Ou ainda, quando o tratamento do paciente exigia que ele ficasse em quarto separado, rotulado nos precedentes como "Diferença de Classe sem Ônus para o SUS"; quer dizer: os médicos constataram 
que era preciso que o paciente ficasse internado em quarto privativo e o doente propôs pagar a diferença. Curiosamente, o Estado não aceitava essa situação. Vedava-se o quarto privativo, mesmo com o pagamento do excedente. Há vários acórdãos nessa linha, dos quais se destacam: Recurso Extraordinário 207.970-7/RS (Relator Ministro Moreira Alves), Recurso Extraordinário 226.835-6/RS (Relator Ilmar Galvão) e Recurso Extraordinário 255.086-8/RS (Relatora Ministra Ellen Gracie).

Desse quadro, exsurgem as questões: qual direito à saúde foi garantido? O de pagar a diferença? Por esse cenário também é possível analisar o nível de cidadania que se encontrava no Brasil.

Gilmar Ferreira Mendes tomou posse como Ministro do STF em 20.06.2002. Antes disso, porém, desenvolveu forte pesquisa acadêmica, especialmente em direito constitucional. O magistrado cursou Mestrado e Doutorado na Alemanha, e exercia a docência (ainda exerce), na mesma área, na Universidade de Brasília (UnB), consoante se pode examinar do curriculum vitae disponibilizado no próprio site do Tribunal: uma análise mais detalhada em seu currículo denota uma forte formação acadêmica voltada justamente às questões constitucionais.

Além da atuação como ministro-julgador propriamente dito, Gilmar Mendes deixou a sua marca no direito à saúde, durante o exercício da Presidência do Supremo Tribunal Federal, seja pela importante convocação da audiência pública sobre judicialização da saúde, seja pela construção teórica grafada nos julgamentos de recursos para suspensão de segurança, suspensão de tutela antecipada e suspensão de liminar de competência privativa da Presidência, como ofertado na Suspensão de Liminar 47-AgR/PE e na Suspensão de Tutela Antecipada 175AgR/CE. No primeiro caso, o então Presidente da Suprema Corte - Ministro Gilmar Ferreira Mendes - convocou uma audiência pública para ouvir médicos, gestores públicos, membros da sociedade civil etc., com o condão de coletar informações sobre o problema da saúde e da sua judicialização no Brasil. A audiência ocorreu 
nos dias 27, 28 e 29 de abril e 4, 6, e 7 de maio de 2009'. Pelo teor dos depoimentos colhidos de diferentes setores, concluiu-se que já existem inúmeras políticas públicas em direito à saúde, nos mais diversos aspectos, de modo que não se trataria propriamente de judicialização das políticas públicas, uma vez que já estavam em atividade (haviam sido implantadas), mas sim de necessidade de intervenção do Judiciário quando elas se mostrassem inefetivas. Portanto, por meio de decisões judiciais, buscar-se-ia a concretude social das políticas já em vigor e não haveria de se falar em sua criação pelas decisões suprarreferidas.

O Ministro Gilmar Ferreira Mendes enfrentou o direito à saúde quando relatava os inúmeros casos de pedidos de suspensão de decisões liminares. Dessa gama, destaca-se o Agravo Regimental na Suspensão de Liminar 47/PE, oportunidade em que trouxe a lume uma vasta leitura sobre o tema, para forjar, dentro da Corte, o conceito de direito à saúde como direito fundamental, o que invariavelmente produziu um aumento de consistência teórica ao julgamento, influenciando sobremaneira os demais ministros nos novos julgamentos sobre a mesma temática. Ao recorte deste artigo, destaca-se como relevante a assertiva do Ministro Eros Grau, no mesmo julgamento, em que categoricamente afirmou, na página 62: "O SENHOR MINISTRO EROS GRAU: - Presidente, vou acompanhar Vossa Excelência [o Ministro Gilmar Mendes], sem dúvida, e não posso deixar de dizer da alta qualidade do voto proferido, que certamente vai ficar marcado neste Tribunal.".

\section{DA RESERVA DO POSSÍVEL A PARTIR DA QUEBRA DE PARADIGMA}

O debate a respeito da possibilidade ou não de efetivação do direito à saúde pelo Judiciário sempre teve como algoz o postulado da reserva do possível. Resumidamente, significa dizer que os recursos são escassos e as necessidades sociais infinitas. Ao Poder Executivo caberia a análise do que é mais importante.

${ }^{1}$ A respeito, conferir o sítio eletrônico da Suprema Corte (BRASIL. STF. Judicialização do direito à saúde). 
Nesta linha, o Estado-juiz não poderia intervir nessas situações justamente porque não haveria recursos infinitos; a contrário disso, os recursos financeiros seriam, pois, escassos, o que obrigou o gestor público a implementar a referida ideia de reserva do possível. Essa forte defesa, reiteradas vezes utilizada como álibi, quer na jurisprudência, quer na teoria, quer pela Administração Pública, é completamente desacreditada pela racionalidade do Supremo Tribunal Federal. Estar-se-ia a tratar de valores constitucionais, segundo a Corte.

Esse novo pensar faz com seja exaltado nos julgamentos um novo nível dos temas a serem tratados como legítimos quando inseridos no debate judicial, de modo que não se deve realizar em grau inferior, no qual questões secundárias como as financeiras venham a tomar papel de destaque, consoante afirma o Ministro Gilmar Mendes, entre outros, no Agravo Regimental na Suspensão de Liminar 47/PE; ou mesmo em nível mais ideológico, como faz o Ministro Marco Aurélio no Recurso Extraordinário 368.564-DF, quando pontuou a sua irresignação como contribuinte, cidadão e juiz pela inércia do Estado, com a ironia de que a concessão do tratamento não deixaria a viúva mais pobre. Deste mesmo acórdão, convém trazer à baila os enunciados postos pelos Ministros Ayres Britto e Luiz Fux, nos seguintes termos: o Ministro Britto explana sobre a comodidade da reserva do possível para o Estado, cuja alegação pelo Poder Público tornou-se uma desculpa cômoda. Em sintonia, o Ministro Fux remonta ao seu posicionamento da época que era Desembargador no Tribunal de Justiça do Rio de Janeiro (TJRJ), depois ministro do Superior Tribunal de Justiça (STJ), para, enfim, como ministro do STF, continuar a votar a favor da efetividade da saúde, com a constatação de que a jurisprudência da Suprema Corte é muito ampliativa quando se trata do tema. O magistrado vai além: traz ao debate a tese da anatomia da esperança, a qual, nos dizeres do prêmio Nobel de Medicina, o Professor Jerome Groopman, provoca nos pacientes a emissão de uma enzima que pode prolongar a vida. Por adotá-la, o Ministro Fux é a favor de que o Estado proporcione aos doentes todo tratamento que venha a alimentar essa esperança, por estar estritamente ligada à dignidade da pessoa humana. 
O Estado do Amazonas interpôs recurso extraordinário com fundamento na reserva do possível em face de acórdão que concedeu ao jurisdicionado o direito ao fornecimento de medicação. Contudo, a decisão monocrática da Suprema Corte analisada vai de encontro à referida reserva do possível. Positiva que a aludida reserva deve estar limitada ao atendimento do mínimo existencial, sem fazer qualquer menção sobre o conteúdo do mínimo, pelo contrário, nada trouxe ao debate o montante a ser gasto pelo Estado naquele processo e o porquê fazia jus aquele jurisdicionado. ${ }^{2}$

A partir da quebra dos paradigmas anteriores, em sede de decisão jurisprudencial do STF, a reserva do possível não tem encontrado guarida nem mesmo com os ministros mais conservadores no que diz respeito à atuação jurisdicional, como o faz o Ministro Ricardo Lewandovski, de cuja lavra se destaca o Recurso Extraordinário n. 628.293-DF, quando se manteve a assertiva de que a reserva do possível deve limitar-se ao mínimo existencial sem, no entanto, fornecer a mínima ideia do que seria mínimo existencial. Neste caso específico, o Estado do Amazonas interpôs recurso extraordinário com o mote de ver reformado acórdão que o obrigava a fornecer medicamentos. $O$ recorrente, com base na escassez de recursos e na necessidade do chamamento da União ao processo, pretendia que seu pleito fosse julgado pela Justiça Federal, o que foi indeferido, inclusive monocraticamente pelo relator, com a justificativa de que o jurisdicionado pode exigir de qualquer dos entes estatais a efetivação do direito à saúde e que esta solidariedade não pode, nunca, ser utilizada como óbice à sua concretude. A decisão foi proferida monocraticamente, o que denota um novo paradigma, porquanto o relator, em seus votos e relatorias, manifestou-se pelo não deferimento de intervenção judicial no direito à saúde com preocupação de usurpação de poderes.

\footnotetext{
2 Trecho do julgado, p. 2: "O direito à saúde é direito constitucionalmente garantido; A reserva do possível está limitada pelo atendimento do mínimo existencial; Sendo o direito a saúde reconhecido como fundamental e de cunho positivo não pode o Estado fazer qualquer alegação para o seu descumprimento." (BRASIL, STF, Recurso Extraordinário, j. 2.08.2011).
} 
No julgamento do Agravo Regimental em Recurso Extraordinário n. 393.175$0-\mathrm{RS}^{3}$, a lide girou em torno do fornecimento de medicamentos gratuitos para portador do vírus HIV. O Estado, neste caso, serve-se do argumento da escassez de recurso para negar o pleito de fornecimento da medicação. $O$ decisum, relatado pelo Ministro Celso de Mello, enfrentou a questão desqualificando os argumentos estatais à luz da efetividade do direito à saúde, como corolário do direito à vida. Os argumentos do Estado foram tipificados como mesquinhos e secundários, diante do problema proposto. ${ }^{4}$

Sobreleva também comentar o pedido de Suspensão de Segurança 4304/CE, impetrado pelo Ministério Público do Estado do Ceará, no qual se pleiteou o fornecimento de medicamento de elevado valor econômico para dois portadores de doença rara, rotulada como Hemoglobinúria. Em sede de liminar, o mandamus foi deferido. Consequentemente, o Estado do Ceará pleiteou a suspensão da medida ao Presidente do Supremo Tribunal Federal sob o fundamento de grave dano à economia do estado cearense, haja vista o elevado valor do tratamento. $O$ acórdão decidiu no sentido de que o alto custo de medicação, por si só, não é motivo hábil a fundamentar o deferimento da suspensão da liminar. ${ }^{5}-6$

\footnotetext{
3 Trechos do julgado: "A INTERPRETAÇÃO DA NORMA PROGRAMÁTICA NÃO PODE TRANSFORMÁ-LA EM PROMESSA CONSTITUCIONAL INCONSEQÜENTE. [...] DISTRIBUIÇÃO GRATUITA, A PESSOAS CARENTES, DE MEDICAMENTOS ESSENCIAIS À PRESERVAÇÃO DE SUA VIDA E/OU DE SUA SAÚDE: UM DEVER CONSTITUCIONAL QUE O ESTADO NÃO PODE DEIXAR DE CUMPRIR. - O reconhecimento judicial da validade jurídica de programas de distribuição gratuita de medicamentos a pessoas carentes dá efetividade a preceitos fundamentais da Constituição da República (arts. $5^{\circ}$, 'caput', e 196) e representa, na concreção do seu alcance, um gesto reverente e solidário de apreço à vida e à saúde das pessoas, especialmente daquelas que nada têm e nada possuem, a não ser a consciência de sua própria humanidade e de sua essencial dignidade. Precedentes do STF." (BRASIL. STF. Agravo Regimental em Recurso Extraordinário 393.175-O - RS, j. 12.02.2006, p. 1524, 1525, respectivamente, grifo nosso).

4 Trecho do mesmo julgado: "Tal como pude enfatizar em decisão por mim proferida no exercício da Presidência do Supremo Tribunal Federal, em contexto assemelhado ao da presente causa (Pet $1.246 / \mathrm{SC}$ ), entre proteger a inviolabilidade do direito à vida e à saúde, que se qualifica como direito subjetivo inalienável assegurado a todos pela própria Constituição da República (art. $5^{\circ}$, 'caput' e art. 196), ou fazer prevalecer, contra essa prerrogativa fundamental, um interesse financeiro e secundário do Estado, entendo - uma vez configurado esse dilema - que razões de ordem éticojurídica impõem ao julgador uma só e possível opção: aquela que privilegia o respeito indeclinável à vida e à saúde humanas." (BRASIL. STF. Agravo Regimental em Recurso Extraordinário 393.175-O-RS, j. 12.02.2006, p. 1529, grifo nosso).

${ }^{5}$ Trecho do julgado: "Na origem, o Ministério Público do Ceará, impetrou mandado de segurança, com pedido liminar, para garantir a Monique Sobreira de Carvalho Moreira e Tiago Moura Sobreira Bezerra, portadores de doença rara denominada Hemoglobinúria.". Trecho do mesmo julgado, p. 2:
} 


\section{CONSIDERAÇÕES FINAIS}

A leitura desses acórdãos, e outros no mesmo diapasão, denotam como direta ou indiretamente estão fundamentados na ausência dos parâmetros rompidos pelas atuações antes mencionadas. É possível também se falar em novos parâmetros e não em ausência de critérios.

Nos termos desta pesquisa, prefere-se a ausência de critérios ante o entendimento de que os rígidos pontos de partida anteriores moldaram por décadas a atuação judicial e a sua retirada acabou fragilizando a argumentação jurídica, a ponto de não se discutirem questões pertinentes como (i) a efetividade ou não daquele novo tratamento ou fármaco se comparado ao oferecido pelo poder público, (ii) o valor a ser gasto pelo ente público e (iii) eventual resultado do tratamento conforme o estágio no qual se encontrar o doente. Aliás, as provas da efetividade ou não do novo tratamento tornaram-se desnecessárias.

Os acórdãos falam doravante em oferecer esperança como fonte de cura. Uma linguagem muito longínqua da ciência médica e sem qualquer critério de gestão do dinheiro público instaurou-se nos novos julgamentos da Corte. Esse argumento suscita uma questão peculiar: o que aconteceria se um gestor oferecesse esperança aos indivíduos com dinheiro público, em ações sem nenhuma

\footnotetext{
"De acordo com o regime legal de contracautela (Leis nos 12.016/09, 8.437/92, 9.494/97 e art. 297 do RISTF), compete a esta Presidência suspender execução de decisões concessivas de segurança, de liminar ou de tutela antecipada, proferidas em única ou última instância, pelos tribunais locais ou federais, para evitar grave lesão à ordem, à saúde, à segurança e à economia públicas." (BRASIL. STF. Suspensão de Segurança 4304/CE, j. 19.04.2011, p. 1).

${ }^{6}$ Trecho do mesmo julgado: "Nesses termos, verifico que a Corte, no julgamento das STAS $n^{\circ} 244-$ AgR e 175 - AgR (Min. GILMAR MENDES, DJE de 30.4.2010) fixou parâmetros que devem nortear o julgador na solução de conflitos que envolvem questões relativas ao direito à saúde. Dentre os critérios fixados, destaco a vedação imposta à Administração Pública no tocante ao fornecimento de medicamento que não possua registro na ANVISA. É que, conforme as informações prestadas pela ANVISA, o fármaco SOLIRIS (eculizumabe) não possui registro no Ministério da Saúde.". Trecho do mesmo julgado, p. 4: "Ademais, o alto custo do medicamento não é, por si só, motivo suficiente para caracterizar a ocorrência de grave lesão à economia e à saúde públicas, visto que a Política Pública de Dispensação de Medicamentos excepcionais tem por objetivo contemplar o acesso da população acometida por enfermidades raras aos tratamentos disponíveis." (BRASIL. STF. Suspensão de Segurança 4304/CE, j. 19.04.2011, p. 3).
} 
comprovação de algum resultado e, ademais, se isso fosse autorizado em violação à lei de responsabilidade fiscal?

Por derradeiro, a ausência de consistência jurídica fica também evidenciada com a completa despreocupação em enfrentar a argumentação jurídica oferecida pela política. Tudo está tão conforme os novos conceitos que não se justifica argumentar ou enfrentar as teses jurídicas da Administração Pública. Eis o novo paradigma jurisdicional em direito à saúde.

\section{REFERÊNCIAS}

BRASIL. Supremo Tribunal Federal. Audiências públicas realizadas. Judicialização do direito à saúde. Disponível em: <http://www.stf.jus.br/portal/audiencia Publica/audienciaPublica.asp?tipo=realizada . Acesso em: 19 set. 2013.

Agravo de Instrumento 232.469/RS. Relator Ministro Marco Aurélio. Requerente: Município de Porto Alegre. Requerido: Loreni de Fátima Santos Serpa. Brasília, DF, 12 de dezembro de 1998. Publicado em 23.02.1999. Disponível em:

<http://stf.jus.br/portal/jurisprudencia/listarJurisprudencia.asp?s1=\%28Al\%24\%2ESC LA\%2E+E+232469\%2ENUME\%2E\%29\&base=baseMo

nocraticas\&url=http://tinyurl.com/nd7prs9j>. Acesso em: 16 out. 2013.

Agravo de Instrumento 238.328/RS. Relator Ministro Marco Aurélio. Requerente: Município de Porto Alegre. Requerido: Ana Luiza Soares de Carvalho. Brasília, DF, 16 de novembro de 1999. Publicado em 18.02.2000. Disponível

em: <http://stf.jus.br/portal/jurisprudencia/listarJurisprudencia.asp?s1=\%28Al\%24\%2ESC $\mathrm{LA} \% 2 \mathrm{E}+\mathrm{E}+238328 \% 2 \mathrm{ENUME} \% 2 \mathrm{E} \% 29+\mathrm{OU}+28 \mathrm{Al} \%$

2EACMS\%2E+ADJ2+238328\%2EACMS\%2E\%29\&base=baseAcordaos\&url=http://ti n yurl.com/p39qk6b>. Acesso em: 16 out. 2013.

Agravo de Instrumento 507.072 - MG. Relator Ministro Joaquim Barbosa. Brasília, DF, 30 de maio de 2006. Publicado em DJU 03.08.2006. Disponível em: <http://stf.jus.br/portal/jurisprudencia/listarJurisprudencia.asp?s1=\%28 Al\%24\%2ESCLA\%2E+E+507072\%2ENUME\%2E\%29\&base=baseMonocraticas\&url = http://tinyurl.com/omga9mt $>$. Acesso em: 16 out. 2013.

Agravo de Instrumento 607/646 - SC. Relator Ministro Ricardo Lewandowski. Brasília, DF, 15 de setembro de 2006. Publicado em DJU 02.10.2006. 
Disponível em: <http://stf.jus.br/portal/diarioJustica/verDiarioProcesso.asp?numDj= 189\&dataPublicacaoDj=02/10/2006\&incidente $=2387166 \&$ codCapitulo $=6 \&$ numMater ia $=143 \&$ codMateria=3 . . Acesso em: 16 out. 2013.

Agravo Regimental 597.182- RS. Relator Ministro Cesar Peluso. Brasília, DF, 10 de outubro de 2006. Publicado em DJU 06.11.2006. Disponível em: $<$ http://stf.jus.br/portal/jurisprudencia/listarJurisprudencia.asp?s1=\%28Al $\% 24 \% 2 E S C L A \% 2 E+E+597182 \% 2 E N U M E \% 2 E \% 29+O U+\% 28 A I \% 2 E A C M S \% 2 E+A$ DJ2+597182\%2EACMS\%2E\%29\&base=baseAcordaos\&url=http://tinyurl.com/a8z 6y88>. Acesso em: 16 out. 2013.

Agravo Regimental no Recurso Extraordinário 273.042/RS. Relator Ministro Carlos Velloso. Requerente: Município de Porto Alegre. Requerido: Carlos Alfredo de Souza Luize. Brasília, DF, 28 de agosto de 2001. Publicado em 11.09.2001. Disponível em: $<$ http://redir.stf.jus.br/paginadorpub/paginador.jsp?docTP=AC\&doclD=335726>. Acesso em: 16 out. 2013.

Agravo Regimental em Recurso Extraordinário 393.175-0 RS. Relator Ministro Celso de Mello. Agravante: Estado do Rio Grande do Sul. Agravada: Luiz Marcelo Dias e outro (A/S). Brasília, DF, 12 de dezembro de 2006. Publicado em 02.02.2007. Disponível em: <http://stf.jus.br/portal/jurisprudencia/listarJurisprudencia.asp?s1=\%28RE\%24\%2ES $\mathrm{CLA} \% 2 \mathrm{E}+\mathrm{E}+393175 \% 2 \mathrm{ENUME} \% 2 \mathrm{E} \% 29+\mathrm{OU}+\% 28 \mathrm{RE} \% 2 \mathrm{EACMS} \% 2 \mathrm{E}+\mathrm{ADJ} 2+3931$ 75\%2EACMS\%2E\%29\&base=baseAcordaos\&url=http://tinyurl.com/b53du76>. Acesso em: 16 out. 2013.

Agravo Regimental na Suspensão de Liminar 47/ PE. Relator Ministro Gilmar Mendes. Agravante: Estado de Pernambuco. Agravado: União. Ministério Público Federal. Ministério Público do Estado de Pernambuco. Município de Petrolina. Brasília, DF, 17 de março de 2010. Publicado em 30.04.2010. Disponível em: <http://stf.jusbrasil.com.br/jurisprudencia/9087061/agregnasuspensao-de-liminar-sl-47-pe>. Acesso em: 16 out. 2013.

Arguição de Descrumprimento de Preceito Fundamental 45 - MC/DF. Relator Ministro Celso de Mello. Brasília, DF, julgado em 29 de abril de 2004. Publicado em DJU 04.05.2004, p. 4-5. Disponível em: $<$ http://www.stf.jus.br/arquivo/informativo/documento/informativo345.htm>. Acesso em: 20 set. 2013.

em:

Gilmar Ferreira Mendes. Curriculum Vitae. 2008. Disponível $<$ http://www.stf.jus.br/arquivo/cms/sobreStfComposicaoCompo sicaoPlenariaApresentacao/anexo/cv_gilmar_mendes_2008maio06.pdf>. Acesso em: 24 set. 2013. 
Agravo Regimental na Suspensão de Liminar 47/ PE. Relator Ministro Gilmar Mendes. Agravante: Estado de Pernambuco. Agravado: União. Ministério Público Federal. Ministério Público do Estado de Pernambuco. Município de Petrolina. Brasília, DF, 17 de março de 2010. Publicado em 30.04.2010. Disponível em: <http://stf.jusbrasil.com.br/jurisprudencia/9087061/agreg-nasuspensao-de-liminar-sl-47-pe>. Acesso em: 16 out. 2013.

Recurso Extraordinário 236.644/RS. Relator Ministro Maurício Corrêa. Requerente: Município de Porto Alegre. Requerido: Carlos Alberto Ebeling Duarte. Brasília, DF, 5 de agosto de 1999. Publicado em 03.09.1999. Disponível em: <http://stf.jus.br/portal/jurisprudencia/listarJurisprudencia.asp?s1=\%28RE\%24\%2ES $\mathrm{CLA} \% 2 \mathrm{E}+\mathrm{E}+236644 \% 2 \mathrm{ENUME} \% 2 \mathrm{E} \% 29$ \&base $=$ baseMo nocraticas\&url=http://tinyurl.com/nmwr2n3>. Acesso em: 16 out. 2013.

Recurso Extraordinário 259.508/RS. Relator Ministro Maurício Corrêa. Requerente: Município de Porto Alegre. Requerido: Patrício Palácio de Souza. Brasília, DF, 8 de agosto de 2000. Publicado em 16.02.2001. Disponível em: <http://stf.jus.br/portal/jurisprudencia/listarJurisprudencia.asp?s1=\%28RE\%24\%2ES $\mathrm{CLA} \% 2 \mathrm{E}+\mathrm{E}+236644 \% 2 \mathrm{ENUME} \% 2 \mathrm{E} \% 29$ \&base=baseMonocraticas\& url=http://tinyurl.com/nmwr2n3>. Acesso em: 16 out. 2013.

Recurso Extraordinário 368.564/DF. Relator Ministro Marco Aurélio. Requerente: União. Requerido: Maria Euridice de Lima Casale. Brasília, DF, 13 de abril de 2011. Publicado em 10.08.2011. Disponível em: <http://stf.jus.br/portal/jurisprudencia/listarJurisprudencia.asp?s1=\%28RE\%24\%2ES $\mathrm{CLA} \% 2 \mathrm{E}+\mathrm{E}+368564 \% 2 \mathrm{ENUME} \% 2 \mathrm{E} \% 29+\mathrm{OU}+\% 28 \mathrm{RE} \% 2 \mathrm{EACMS} \% 2 \mathrm{E}+\mathrm{ADJ} 2+3685$ 64\%2EACMS\%2E\%29\&base=baseAcordaos\&url=http://tinyurl.com/k59qe3j>. Acesso em: 16 out. 2013.

Recurso Extraordinário 628293/DF. Relator Ministro Ricardo Lewandoski. Requerente: Estado do Amazonas. Requerido: Ministério Público do Estado do Amazonas. Brasília, DF, 2 de agosto de 2011. Publicado em 04.08.2011. Disponível em: <http://stf.jusbrasil.com.br/jurisprudencia/22925013/recursoextraordinario-re-628293-df-stf>. Acesso em: 16 out. 2013.

Suspensão de Segurança 4304/CE. Relator Ministro Cezar Peluso. Requerente: Estado do Ceará. Requerido: Relator do MS. Impetrante: Ministério Público do Estado do Ceará. Brasília, DF, 19 de abril de 2011. Publicado em 02.05.2011. Disponível em: <http://stf.jus.br/portal/jurisprudencia/listarJurisprudencia.asp?s1=\%28SS\%24\%2ES $\mathrm{CLA} \% 2 \mathrm{E}+\mathrm{E}+4304 \% 2 \mathrm{ENUME} \% 2 \mathrm{E} \% 29$ \&base=baseMonocraticas\&url=http://tinyurl.co m/luhdqpx>. Acesso em: 16 out. 2013.

Suspensão de Tutela Antecipada 175 AgR/CE. Relator Ministro Gilmar Mendes. Agravante: União. Agravado: Ministério Público Federal. Clarice Abreu de Castro Neves. Município de Fortaleza. Estado do Ceará. Brasília, 
DF, 17 de março de 2010. Publicado em 30.04.2010. Disponível em: $<$ http://redir.stf.jus.br/paginadorpub/paginador.jsp?docTP=AC\&doclD=610255>. Acesso em: 16 out. 2013. 